\title{
The L2 status factor and the declarative/procedural distinction
}

\author{
Camilla Bardel and Ylva Falk \\ Stockholm University
}

This chapter deals with the assumed qualitative difference between the learning of a chronologically true L2 and the subsequent learning of an L3, and the related issue of transfer from L2 into L3. In fact, some recent studies show that L2 can take on a stronger role than L1, as transfer source in L3 learning. A possible explanation to this phenomenon is a strong impact of the L2 status factor, which we argue is due to the higher degree of cognitive similarity between L2 and L3 than between L1 and L3. Further theoretical support to the L2 status factor, as one of several possibly interacting factors that may determine the transfer source (L1, L2/s), is here provided by a neurolinguistic account, suggesting that the distinction between declarative and procedural memory can account for what might lie behind it.

Keywords: Third language learning, L2 status factor, procedural memory, declarative memory, implicit linguistic competence, explicit metalinguistic knowledge, psychotypology, typology, Cumulative Enhancement Model, Typological Primacy Model, age of onset, outcome, learning situation, awareness, transfer. 


\section{Introduction}

During the past two to three decades, several studies on third language (L3) learning ${ }^{1}$ have drawn attention to a qualitative difference between the learning of a chronologically true second language (L2), i.e., the very first language encountered after the mother tongue (L1), and the subsequent learning of an L3. Although many studies show that L1 plays a role in L3 learning, some recent studies indicate that L2 can take on a stronger role than L1 in the initial state of L3 syntax (e.g. Bardel \& Falk 2007; Bohnacker 2006; Falk \& Bardel 2011; Leung 2005; Rothman \& Cabrelli Amaro 2010). A possible explanation as to why the L2 can in some cases outrank the L1, put forward by Williams and Hammarberg (2009 [1998]) in their longitudinal case study of Swedish L3 vocabulary, is that of the L2 status factor. Hammarberg (2001) defines the L2 status factor as “a desire to suppress L1 as being 'non-foreign' and to rely rather on an orientation towards a prior L2 as a strategy to approach the L3" (Hammarberg 2001: 36-37). This phenomenon was observed early on by Meisel (1983), who labelled it foreign language effect (cf. also Ecke \& Hall 2000, where it is called Fremdspracheneffekt). The L2 status factor has since then been considered as one of several possibly interacting factors that may determine the transfer source (L1, L2/s) in many studies on L3 vocabulary (e.g. Cenoz 2001; De Angelis 2005, 2007).

Bardel and Falk (2007) suggested that L2 status was a factor also in the learning of L3 syntax, as they found that L2 was preferred as a transfer source in L3 syntax in the initial state of a group of L3 learners. Subsequently, Falk and Bardel (2011) tested the L2 status factor hypothesis in a larger number of intermediate L3 learners and found the same tendency.

\footnotetext{
${ }^{1}$ Adopting the implicit/explicit perspective to language appropriation, following Paradis (2004, 2008, 2009), we use the terms L2 and L3 learning as opposed to L1 acquisition. However, we acknowledge the use of acquisition as a generic term, used by many of the researchers we are referring to, for instance those working in the UG framework.
} 
Several introspective and anecdotal comments referred to in previous L3 studies, as well as an increasing number of large-scale studies report transfer from L2 in L3 learning and use. Still, one wonders why L3 learners would feel a need to suppress L1 and prefer to rely on L2 in their approach to the L3. According to Falk and Bardel (2010 and 2011), the L2 status factor is an outcome of the higher degree of cognitive similarity between L2 and L3 than between L1 and L3. In this paper, we aim at providing further theoretical support to the L2 status factor, suggesting that the distinction between declarative and procedural memory (Paradis 2004, 2009; Ullman 2001, 2005) can provide a neurolinguistic account for what might lie behind it.

\section{A short overview of important factors for transfer into $L 3$}

Different factors have been suggested to explain why one, and not the other, language is transferred in a specific situation. While some studies point at the L2 status as a decisive factor, other factors have been discussed in the research on L3 learning: for instance, proficiency level in both the L2 and L3 (e.g. Bardel \& Lindqvist 2007; De Angelis 2007; Lindqvist 2010), recency of use of a particular language, degree of formality and age of onset (for overviews, see, e.g. De Angelis 2007, Falk \& Bardel 2010). However, the factor that has received most attention is probably the typology factor. By typology, L3 researchers sometimes seem to imply slightly different things ${ }^{2}$ : it can be understood either in terms of the background languages and the target language (TL) involved being related or as particular structures being similar in a background language and the TL, independently of language relatedness. Furthermore, it can be either postulated by the researcher on linguistic scientific

\footnotetext{
${ }^{2}$ See discussions in De Angelis (2007: 22-33), Falk and Bardel (2010: 193-194) and Montrul, Dias and Santos (2011: 24).
} 
grounds or purportedly apprehended by the learner (i.e. psychotypology in the sense of Kellerman 1983, cf. Rothman 2010, 2011).

There are many studies that support the role of typology when it comes to determining the transfer source in L3 vocabulary, in the sense that they show that the most similar and more closely related background language is opted for as transfer source, independently of its being the L1 or an L2 of the learner. For example Cenoz $(2001,2003)$ examines Basque and Spanish as background languages and English as TL, Ringbom (1987) studies Finnish and Swedish as background languages and L3 English and Singleton and O' Laoire (2006) investigate L3 learners of French with Irish and English as L1/L2. An early study of L3 syntax where typology seems to come into play, according to the author, is Leung (2005), where two groups of learners of French were compared. One group were learning French as an L3 (L1 Cantonese, L2 English) and one group were learning French as an L2 (L1 Vietnamese). The L3 group transferred (morpho)syntax from English L2 into L3 French (i.e., they spelled out the article), and the L2 learners transferred their L1 Vietnamese (i.e., they left out the article). On the basis of these results, Leung concluded that

the more languages there are in the pool of prior linguistic knowledge at the language learner's disposal, the more beneficial it will be for his subsequent acquisition of additional languages, especially those that are typologically-related. (Leung 2005: 58).

However, it could also be hypothesized that it was a foreign language effect, that is, the L2 status factor that induced those learners who had L2 knowledge of English to transfer syntactic structures from their L2 to their L3.

The typology factor has also been emphasized in two recent models for L3 syntax: the Cumulative Enhancement Model (CEM, Flynn, Foley \& Vinnitskaya 2004) and the Typological Primacy Model (TPM, Rothman 2011). According to the CEM (Flynn et 
al. 2004: 5), all languages known to the L3 learner can influence the development of subsequent learning:

Language learning is cumulative. All languages known can potentially influence the development of subsequent learning. The learner's L1 does not play a privileged role in subsequent acquisition (Flynn et al. 2004: 5).

Clearly, Flynn et al. advocate a facilitative effect of any previously acquired/learned language (L1 or L2):

Where appropriate, other languages known can enhance subsequent language acquisition. This claim contrasts with models that either implicitly or explicitly characterise subsequent language learning fundamentally in terms of a deficit model (e.g. negative transfer, and interference). (Flynn et al. 2004: $5)$.

The study of Flynn at al. (2004) concerned the acquisition of the English CP structure, and compared a number of studies of different groups of learners, children acquiring English L1, adults learning English L2 (Spanish or Japanese L1) and children and adults learning English L3 (Kazakh L1, Russian L2). Crucially, the CP structure differs in the languages involved, in such a way that Kazakh and Japanese on the one hand are head-final and left-branching and Spanish, Russian and English on the other hand are head-initial and right-branching. The results reported show that learners of English L3 who have Kazakh L1 and Russian as L2 learn the English CP structure with more ease than those who do not have any background language with such a CP structure (Japanese L1 speakers learning English as L2).

Some questions arise from the way the claims of the model are formulated on the basis of these results: First of all, how does the learner know which of his/her background 
languages matches the TL (cf. García Mayo \& Rothman this volume) ${ }^{3}$ Secondly, considering the perspective of the L2 status factor, the conclusions that any prior knowledge can have a facilitative effect are confounded by the fact that it is the L2 and not the L1 that transfers in the case of the L3 learners. The results could also be an effect of the L2 status factor. This possibility is in fact acknowledged by the authors:

$[\mathrm{T}]$ he adult results we report here are left confounded with respect to the role of an immediately prior learned language. Could it be that the last learned language determines the next language learned in some sense. Such an explanation is compatible with the results reported here as well. Subsequent testing demands that we consider the acquisition of an L3 by a speaker in which the CP properties, for example, match in the L1 and the L3 but not the L2. (Flynn et al. 2004: 13-14).

In a number of studies, Rothman (e.g., 2010, 2011) has attempted to tease apart the typology and the L2 status factor by investigating L3 learners of Brazilian Portuguese with either L1 English and L2 Spanish or the other way round, studying the acquisition of features that either do or do not match each other in the two Romance languages. According to the TPM, (psycho)typology determines which of the two languages will be transferred, that is to say, in L3 learning the source language for transfer is determined on the basis of the learners' perception of how similar languages are at a general level. This would lead the learners to transfer from Spanish to Brazilian Portuguese, independently of the L1/L2 status, since Spanish is without doubt more similar to Brazilian Portuguese than English at a general level.

\footnotetext{
${ }^{3}$ Even though the L3 learners in Flynn's study are post-critical period learners, and can be assumed to be learning the L3 explicitly (Paradis 2009), it can be questioned, at least for the initial state, how they could know enough about the TL to be able to choose the optimal transfer source. At later stages, learners may or may not observe what is similar to or different from a previously acquired/learned language, but the capacity of doing that will vary inter-individually depending on the learner's degree of metalinguistic knowledge about L1 and L2, as well as other factors, such as IQ, motivation, etc. (cf. Paradis 2009: 120).
} 
Importantly, according to the TPM, both L1 and L2 transfer can lead to either target like or non-target like L3 structures. The studies by Rothman show that both L1 and L2 can play a role when Spanish and Brazilian Portuguese are involved, and then independently of the similarity of a particular structure, thus indicating that the typology factor can rule out the L2 status factor when the L1 is closely related and globally similar to the L3. As all the studies that speak in favour of the TPM, in the sense that a closely related L1 influences L3, concern Spanish and Brazilian Portuguese as either influencing language or TL (see also Montrul, Dias \& Santos 2011), it remains unclear exactly how closely related the languages in question must be in order for the L1 to override the L2 as a transfer source.

\section{The L2 status factor: background}

A number of L3 studies, many of which consider the learning of Germanic languages (Bardel \& Falk 2007; Bohnacker 2006; Falk \& Bardel 2011; Williams \& Hammarberg 2009 [1998]), show that if a learner has more than one background language at her disposal, the L2 can in some situations outrank the L1 and become a more important transfer source. According to Williams and Hammarberg (2009 [1998]) the L2 status factor enables the L2 (German in this case) to be the standard option in the role of "external supplier language", that is, a language other than the TL (Swedish) that supplies the interlanguage with linguistic material during the process of speech production. Williams and Hammarberg reach the conclusion that the L1 on the one hand was used in a conscious way, in situations where the informant deliberately decided to leave the foreign language mode and use L1 English (which she knew that the interlocutor has good knowledge of). The L2, on the other hand, was used more 
subconsciously in word constructions or insertions of words that for some reason (probably low proficiency) would not be activated in the TL.

In a study on L3 syntax, Bardel and Falk (2007) suggested that the L2 status factor determined the transfer source, independently of the relative typological similarity or genetic relatedness of the languages involved. The study compared two groups' learning of sentence negation in Swedish and Dutch as an L3 and concerned mainly the initial state but also the development towards target-like use of the structure in question in a series of ten recordings. The negation placement in Swedish and Dutch is related to the finite verb being raised to the second place in the main clause (the V2 property). One group of learners (the English L2 group, n=5) had an L1 with V2 and an L2 without V2 (English), and the other group (the Dutch/German L2 group, $\mathrm{n}=4$ ) had an L1 without V2 and an L2 with V2 (either Dutch or German). ${ }^{4}$ The results showed that during the first recording, that is, at the very first acquaintance with the TL, the Dutch/German L2 group had no major problems in placing the negation post-verbally (96\% correct utterances with sentence negation, as summarized in Falk 2010: 111). On the contrary, the English L2 group displayed incorrect pre-verbal placement of the negation of the following kind: ${ }^{5}$

$$
\text { Jag inte går till universitetet. (TL: Jag går inte till universitetet) }
$$

I not walk to university-the

'I don't walk to the university'

In total, the English L2 group displayed this preverbal negation in $66 \%$ utterances. The differences between the groups were significant. The study comprised two data collections. In

\footnotetext{
4 The low number of informants might be seen as a caveat when interpreting the findings.

${ }^{5}$ The English L2 group displayed this word order with both thematic and non-thematic verbs (see discussion in Bardel \& Falk 2007: 475-478).
} 
data collection A the difference was significant in a chi-square test $(\mathrm{p}<0.01)$ and in data collection B the difference was highly significant $(p<0.001)$, see Bardel and Falk (2007: 475478) for details. The differences between the groups were attributed to transfer from the L2s respectively and the results were explained by the L2 status factor playing a role also at the syntactic level in L3 learning.

In a subsequent study (Falk \& Bardel 2011), the impact of the L2 status factor was further tested in two groups of learners at an intermediate level of German L3, one with L1 French and L2 English (the English L2 group, n=22) and one with L1 English and L2 French (the French L2 group, $\mathrm{n}=22$ ). The study concerned the learning of the placement of object pronouns in German. A grammatical judgment correction task of 60 items was used. The structure in question displays both an inter-language asymmetry (German-French in the main clause as seen in (2a) and (2b), and German-English in the subordinate clause (3a) and (3c)) and an intra-language asymmetry (German main clauses vs. subordinate clauses, see (2a) and (3a)) and this makes it possible to distinguish L1 transfer from L2 transfer.

(2) a. Ich sehe ihn.

S V Objprn

b. Je le vois.

S Objprn V

c. I see him.

S V Objprn 
(3) a. Du weißt dass ich ihn sehe

\section{S Objprn V}

b. Tu sais que je le vois.

S Objprn V

c. You know that I see him.

S V Objprn

The ungrammatical German stimuli were of the following kind (4 and 5):

(4) German *Ich ihn sehe. $\quad$ (TL: Ich sehe ihn)

(5) German *Du weißt dass ich sehe ihn (TL: Du weißt dass ich ihn sehe)

As summarized in Falk (2010: 112), the results from the ungrammatical stimuli displayed the following pattern: The English L2 group scored only 39\% correct on ungrammatical sentences reflecting English word order (cf. the French L2 group's accuracy rate of 83\% on these structures), and the French L2 group scored only $29 \%$ correct on ungrammatical sentences reflecting French word order (cf. the accuracy rate of 93\% for the English L2 group). This clearly indicates a negative transfer effect from their L2. The differences in response pattern from the two groups were significant in a chi-square test for the ungrammatical sentences with English word order, $\chi^{2}($ df. $1, N=477)=95.70, p<0.001$, and for the ungrammatical sentences with French word order, $\chi^{2}($ df. $1, N=525)=231.14, \mathrm{p}$ $<0.001$ (see Falk \& Bardel 2011: $75-76$ for discussion). These results clearly support the predictions made by the L2 status factor, also in language learning beyond the initial state. In Falk and Bardel (2011), the L2 status factor was discussed in terms of a hypothesis, the L2 
Status Factor Hypothesis, which would predict transfer from L2 (and not L1) in L3 learning, and also the rationale for its impact. Williams and Hammarberg (2009 [1998]) had suggested that the L2 received a special status (in relation to the L3) because the learner wanted to sound foreign, and not like a native speaker of her L1. Falk and Bardel (2011) drew attention to a number of differences between a native language and a non-native language that might explain why an L2 is favoured as transfer source in L3 learning. A formally learned L2 and a formally learned L3 have many cognitive and situational features in common that they do not share with an L1. For instance, L2 and L3 are learned in similar manners, the foreign language learner (as opposed to the L1 acquirer) is aware of the fact that (s)he is learning a language, and s/he makes use of various strategies in a way that is not the case in L1 acquisition (see also Falk \& Bardel 2010, 2011).

\section{A model for L3 learning (Falk \& Bardel 2010, 2011)}

There are thus a number of features that L2 and L3 learning have in common. In Falk and Bardel (2010, 2011), it was suggested that the L2 status factor is an outcome of the higher degree of similarity between L2 and L3 than between L1 and L3, regarding age of onset, outcome, learning situation, degree of metalinguistic knowledge, learning strategies and degree of awareness in the process of language appropriation.

The L1 is the language that an individual has acquired before other languages, and it is also normally the most commonly used language (which would give the recency factor a high score) and it is also normally the language in which the speaker has the highest degree of proficiency. Then why would L2 be more easily transferred in some situations? As we see it, the differences just mentioned between the acquisition of an L1, and the learning of an L2 and 
an L3 might as a matter of fact account for why L2 is often present and sometimes even preferred over L1 as transfer source. The following illustration, inspired by Hufeisen (1998: 171-172), indicates the increased number of factors that come into play when L3 learning is taking place. ${ }^{6}$

@@ Insert BAR1.tiff here

As within the generative framework (cf. Chomsky [1965] and later works), input is assumed to interact with innate language acquisition prerequisites in L1 acquisition. In true L2 learning, there are two important additional factors, encyclopedic knowledge and knowledge of L1. By the time the learners starts learning an L3 s/he has already come into contact with at least one non-native language.

Obviously, these differences between L1, L2 and L3 are not categorical, but will apply more or less, depending on internal and external factors, such as motivation, age, acquisitional/learning setting, etc. The age of onset for an L2 may vary from very early in childhood, as in early consecutive bilingualism, to later stages in the life span. Also, the acquisitional/learning setting may vary from predominantly informal acquisition, as is the case for instance in bilingual environments, to more formal settings, such as foreign language learning in the classroom. It can be assumed, however, that L3 learners, especially those who have learned the L2 in a formal setting, are aware of the fact they are learning a new language, and have acquired metalinguistic awareness (for instance awareness of the fact that there are differences and similarities between languages) and learning strategies that may

\footnotetext{
${ }^{6}$ For more recent and elaborated versions of the model, see Hufeisen and Marx (2007) and Hufeisen (2010).
} 
facilitate foreign language learning. They are familiar with at least some of the efforts and methods that are required from a learner in order to succeed (cf. e.g. Jessner 2006; Towell and Hawkins 1994; Wood Bowden, Sanz \& Stafford 2005). Crucially, the role of the L2 status factor is important in formal, adult learning of a foreign language. We do not claim, for instance, that the L2 factor comes into play in learners who have acquired an L2 naturally in pre-adolescent age, when later learning an L3. In the case of early bilinguals or L2 users with a very high proficiency level it might be the case that the L2 takes on an L1-like status. In such cases, it is reasonable to assume that the L2 status factor loses its impact on the L3 learning process. This remains, however, to be investigated.

\section{A neurolinguistic approach to L3 learning ${ }^{7}$}

A neurolinguistic framework which we believe would support the Falk and Bardel model $(2010,2011)$ is the declarative/procedural memory elaborated by Paradis (1994, and further specified in 2004, 2009).

Within the framework of the implicit/explicit perspective (...), all late-learned languages (L2, L3, Ln) are sustained to a large extent by declarative memory. As such, they are more likely to manifest dynamic interference from one another than from the native language(s). (Paradis 2008: 344).

\footnotetext{
${ }^{7}$ In the last decade there has been an increasing interest in how neuroimaging (NI) studies can contribute to our understanding of non-native language acquisition, see for instance Fabbro (2001) and the special issue on Neuroimaging and research into second language acquisition (Sabourin 2009), but see Paradis (2004, Ch. 6), and the special issue of Brain and Language devoted to the problems related to neuroimaging (see editorial by Sidtis 2007). As pointed out by Sabourin (2009: 6), all issues raised in NI research are the same as in "traditional" L2 acquisition research, such as for instance the role of proficiency, age of acquisition, ultimate attainment, language transfer, method of acquisition, aptitude and motivation.
} 
The declarative and the procedural memory systems are well studied and they constitute a powerful basis for predictions about language acquisition within a neurolinguistic approach. ${ }^{8}$ Paradis (1994) was the first to suggest the fundamental difference between procedural and declarative memory in relation to implicit linguistic competence and explicit metalinguistic knowledge, respectively (cf. Paradis 2009, chapter 1). According to Paradis (2009: x), our capacity of verbal communication includes linguistic competence (phonology, morphology, syntax and the lexicon - which contains morphosyntactic properties) and metalinguistic knowledge (conscious knowledge of facts about languages, including vocabulary - word form-meaning relationships). Implicit linguistic competence and explicit metalinguistic knowledge are neurolinguistically distinct (and they may be dissociated by pathology) and have different memory sources (Paradis 2009: $\mathrm{x}-\mathrm{xi}$ ). Implicit linguistic competence is sustained by procedural memory and explicit metalinguistic knowledge by declarative memory. They involve different types of cerebral representation: implicit linguistic competence involves procedural, non-conscious representations that rely on the right cerebellum, the left neostriatum, other basal ganglia, and circumscribed perisylvian cortex, while explicit metalinguistic knowledge involves declarative, conscious representations that rely on the hippocampal system: mesial temporal lobe, parahippocampal gyri, and anterior cingulate cortex (Paradis 2009: 139-140).

According to Paradis' perspective, in L1, procedural memory sustains implicit linguistic structure (phonology, morphology, syntax and the lexicon) while declarative memory sustains vocabulary (words as form-meaning pairs). ${ }^{9}$ While L1 grammar is implicitly

\footnotetext{
${ }^{8}$ Cf. Ullman $(2001,2004,2005)$ for the Ullman version of the declarative/procedural (DP) model and how it applies to L2.

${ }^{9}$ Also according to Ullman, declarative memory underlies lexical information. Ullman distinguishes between the “mental lexicon” and "mental grammar", and does not make a distinction between 'vocabulary' and 'lexicon' as Paradis does. In Ullman (2004) 'the term 'lexicon' is used solely to refer to the 'mental lexicon' - that is, a repository of stored information" (Ullman 2004: 233, note 1). No rule-based computations are carried out in the
} 
acquired and sustained by procedural memory, L2 grammar ("to the extent that teaching of L2 is formal", Paradis (2009: x)) is based on explicit knowledge, and sustained by declarative memory, which also takes care of vocabulary knowledge in both L1 and L2. This means that while vocabulary is sustained by declarative memory in L2 as well as in L1, there is a more obvious difference between L1 and L2 (Ln) when it comes to phonology, morphology, syntax and the morphosyntactic properties of the lexicon. These latter components are acquired implicitly in L1, but learned explicitly in L2 (Ln).

In the same vein, Ullman $(2001,2005)$ discusses the differences between processing linguistic forms in L1 and in L2; whereas computing grammar in the L1 is dependent on procedural memory, the L2 grammar is assumed to be dependent on declarative memory, at least to a greater extent. In sum, an L2 is more dependent on declarative memory as a whole, and, according to Ullman (2001) as well as Paradis (1994, 2004, 2009), only with increased proficiency is there a shift towards the procedural memory for an L2. ${ }^{10}$

Returning to the cognitive differences between L1 and L2 (Ln) suggested by Falk and Bardel (2010, 2011), the Paradis framework allows us to develop the idea of dissimilarity between native language and non-native languages.

As for the age of onset, Paradis suggests an "optimal period" around 2-5 years for acquiring implicit linguistic competence (Paradis 2009: 113ff), after which languages are

\footnotetext{
mental lexicon as opposed to in the mental grammar. What Paradis calls the lexicon is part of the implicit grammar, whereas vocabulary is subserved by declarative memory. Ullman's 'mental lexicon' corresponds to Paradis' 'vocabulary'. Paradis maintains that the implicit morphosyntactic properties of words are part of what Ullman calls the (implicit) 'mental grammar'.

${ }^{10}$ The distinction between implicit and explicit knowledge is well known from discussions in the field of grammar teaching, where the different viewpoints were known as the non-interface hypothesis (Krashen 1981), and the interface hypothesis (weak version: Rutherford \& Sharwood Smith 1988). According to Krashen (1981), explicit, declarative knowledge of grammar cannot lead to implicit knowledge. That these systems are also neurolinguistically distinct provides strong support for the L2 status factor hypothesis, as pointed out by an anonymous reviewer.
} 
learned rather than acquired ${ }^{11}$. When an L2 $(\mathrm{Ln})$ is learned after this period, declarative representations mediate language performance. Also, according to Ullman (2001: 108), the "greater age-of-exposure sensitivity of grammar than of lexicon leads to a shift of reliance from procedural memory in L1 to declarative memory in L2". Hence, in L2 "linguistic forms that are compositionally computed by grammar in L1 may simply be memorized in the lexicon, like words or idioms" (Ullman 2001: 109). While children younger than 4-5 years acquire an L2 in the same way they acquire the L1 (implicitly, by means of the procedural memory), learning a language after the optimal period means relying more on declarative memory for all components of language, not only vocabulary, but also syntax and phonology. Because vocabulary learning relies on declarative memory even in L1, there is no optimal period for learning new words (Paradis 2009: 114). The same goes, of course, for the learning of explicit grammatical rules.

As for outcome, there are examples of L2 users that reach a near-native level. For instance, Abrahamsson and Hyltenstam $(2008,2009)$ show that L2 speakers of Swedish had reached such high proficiency that they were assumed to be native Swedes by Swedish L1 speakers, although they scored lower than a control group of native speakers on a variety of language tasks and tests.

Such high proficiency levels in an L2 can often be accounted for by speeded-up control of declarative representations; however, through frequent use of the language, L2 speakers can eventually shift from heavy reliance on a metalinguistic (explicit) knowledge to a more developed implicit linguistic competence, as stated by Paradis:

In late L2 appropriation, metalinguistic knowledge precedes implicit linguistic competence. In the best

\footnotetext{
11 This reasoning does not imply that all aspects of the L1 are acquired. Some aspects of the L1 related to literacy (spelling, stylistic variation etc.), and (as already mentioned) word form-meaning relationships, are learned in L2 as well as in L1. What is of importance here is that after the optimal period, declarative memory and explicit metalinguistic knowledge seem to play a much more significant role than do procedural memory and implicit competence - for all aspects of language. After this period languages - the L2 as well as aspects of the L1 - are basically learned.
} 
of circumstances, implicit linguistic competence is acquired independently and its use gradually replaces that of metalinguistic knowledge. The two may be used in alternation or in parallel; they complement each other but do not interact. Some aspects (e.g. morphology or syntax) may be automatized while others (e.g. phonology) continue to be controlled - one more illustration of the neurofunctional modularity of the components of linguistic competence. (2009: 101)

Thereby extensive practice can lead to automatization of morpho-syntax, something that manifests itself in performance systematicity, and basically 'looks like' the performance of native speakers.

"[A]n increasing amount of experience (i.e., practice) with a language should lead to better learning of grammatical rules in procedural memory, which in turn should result in higher proficiency in the language" (Ullman 2001: 118). Such a position is shared by Paradis (2004, 2009), who reckons that "it is not theoretically impossible, but that in practice, it is at best very rare that the L 2 grammar in its entirety will be internalized and hence subserved by procedural memory" (Paradis 2009: 15-16). Paradis (2004) suggests a possible change from relying on metalinguistic knowledge to relying on implicit linguistic competence acquired through frequent use of the learned grammatical rules, although these are seen as two different knowledge bases working in parallel, but separately, and without interaction (Paradis, 2004, 2009). Importantly, both Paradis' and Ullman's views support the idea that an L2, in which the learner has a very high level of proficiency, may reach an L1-like status: Implicit acquisition can take place in informal settings and when there are other preconditions for developing higher levels of proficiency, such as long time exposure and strong affective motivation.

Closely connected to the issues of age of onset and outcome is that of learning situation (natural/informal vs. classroom). While L1 is always acquired in a natural context, the L2 learned after a the optimal period is often studied in a classroom setting. In fact, Paradis distinguishes between the term acquire which he uses to refer only to implicit (non- 
conscious) items and processes, and the term learn, which is used only to refer to explicit (conscious) items and processes (2009: xiii).

We have also suggested that the degree of metalinguistic knowledge varies between L1 and L2/L3, when it comes to grammar. This line of reasoning is supported by Paradis' distinction between implicit linguistic competence (sustained by procedural memory) and explicit metalinguistic knowledge (sustained by declarative memory), since according to this theory, L1 grammar is acquired implicitly, which is not the case in an L2/L3 learned after the optimal period.

The fundamental neurolinguistic difference between L1 and L2 syntax concerning declarative and procedural memory sources and the different kinds of knowledge related to them might explain the results found in studies on L3 syntax (Bardel \& Falk 2007; Bohnacker 2006; Falk \& Bardel 2011; Klein Gunnewiek 2000; Leung 2005). As far as vocabulary is concerned, many L3 studies indicate transfer from both L1 and L2 into L3. At first thought, this might seem contradictory, but we find it coherent to assume that all languages (L1, L2 and L3) interact in a similar way since vocabulary knowledge is accounted for by the same declarative knowledge in all languages, non-native as well as native.

However, as is interesting to note, Paradis (2009) makes a distinction between content and function words. L1 function words are known implicitly and stored in procedural memory, while content words constitute vocabulary, which, as we have seen, is subserved by declarative memory:

Grammatical words [...] which are processed as part of the syntax by L1 speakers tend to be treated as open-class words by late L2 speakers [...] who use declarative memory to process the morphosyntactic constructions they have not internalized (Paradis 2009: 18). 
Following Paradis, function words thus could be said to have a "vocabulary status" in both L2 and L3 (but not in L1) and are thus likely to be transferred into L3 from L2 rather than from L1 (if at all). In fact, several studies on L3 production have shown differing tendencies when it comes to content and function words. While content words are often transferred from both L1 and L2 into L3, these studies indicate that function words are mainly transferred from the L2 and not from the L1 (e.g. Ringbom 1987; Stedje 1977; Vildomec 1963), as in the following examples of adult L3 learners of Swedish, reported in Sjögren (2000).

(6)

$$
\text { Dina (L1 Dutch) Or en domare... }
$$

Or a judge

[regular font: Swedish, italic: English]

(7) Gina (L1 German) Blommor pour, för servitrisen.

Flowers for, for waitress-the

[regular font: Swedish, italic: French]

The tendency to transfer function words from L2, rather than from L1, into L3 (as in 6 and 7) supports the idea that content words and function words have the same status in an L2 but not in L1 (Paradis 2009). 


\section{Implications and future directions}

A neurolinguistic framework seems to be highly relevant for studies on the role of L1 and L2 in L3, both regarding syntax and vocabulary. It offers a possible basis for the L2 status factor hypothesis. We acknowledge the role of other factors in L3 learning, which may interact with the L2 status factor to varying degrees, such as for instance the psychotypology factor, which depends on the learner's apprehension of proximity of the background languages and the TL. Apprehension of similarity does in fact imply some degree of metalinguistic knowledge of the involved languages, and declarative memory will therefore be involved in processes related to psychotypology. It seems reasonable to assume that the closer the relationship and the higher the degree of similarity of one background language and the TL, the stronger the option for that particular language to be the default transfer source, especially if the learner has developed a high metalinguistic knowledge for that language (something which is of course possible also in the L1, as a function of literacy). An interesting way forward could be to examine language combinations where L1 and L3 are very closely related like for instance Swedish and Norwegian and the L2 is more distant and less transparent, like, for instance, English or even a further remote language, such as for instance Finnish, if such learners are found. This would provide an interesting background in order to investigate if learning new languages that are so closely related to L1 is anything other than a relexification process (cf. Falk 2010). Syntactic - and phonological - L1 transfer in such a case could indicate that the learners continue to rely on L1 implicit competence, while learning and use of TL vocabulary would rather imply that explicit (metalinguistic) knowledge is at hand. ${ }^{12}$ Another interesting aspect to take into consideration would indeed be a high degree of metalinguistic awareness of the L1, which could be captured if comparing students from different cultural backgrounds,

\footnotetext{
${ }^{12}$ As pointed out by an anonymous reviewer, motivation might be a factor, as in all cases of L2/L3 learning. Individual learners may strive to reach a native-like level of the TL, while others are happy with learning words that they assume are needed for communication purposes.
} 
considering the fact that educational systems vary in different countries, as concerns the degree of attention given to form in the teaching of the first language.

In short, up to now, the L2 status factor makes strong predictions for both negative and positive transfer from L2 into L3, when the L2 is learned in a similar manner as the L3 is (i.e. we have only considered formally learned L2s and L3s), and when the (psycho)typology of the involved languages is not of extreme similarity. Future studies will need to test the impact of the L2 status factor in L3 learning under different learning conditions and with different language combinations in order to set the exact limitations of the factor.

\section{References}

Abrahamsson, N. \& Hyltenstam, K. 2008. The robustness of aptitude effects in near-native second language acquisition. Studies in Second Language Acquisition 30(4): 481-509.

Abrahamsson, N. \& Hyltenstam, K. 2009. Age of onset and nativelikeness in a second language: listener perception versus linguistic scrutiny. Language Learning 59(2): 349-306.

Bardel, C. \& Falk, Y. 2007. The role of the second language in third language acquisition: The case of Germanic syntax. Second Language Research 23(4): 459-484.

Bardel, C. \& Lindqvist, C. 2007. The role of proficiency and psychotypology in lexical crosslinguistic influence. A study of a multilingual learner of Italian L3. Atti del $6^{\circ}$ Congresso Internazionale dell'AssociazioneItaliana di Linguistica Applicata.[Proceedings from the 6th international conference of the Italian association of applied linguistics]. Naples 9-10 February 2006.

Bohnacker, U. 2006. When Swedes begin to learn German: From V2 to V2. Second Language Research 22(4): 443-486.

Cenoz, J. 2001. The effect of linguistic distance, L2 status and age on cross-linguistic influence in third language acquisition. In Cross-linguistic influence in third language 
acquisition. Psycholinguistic perspectives, J. Cenoz, B. Hufeisen \& U. Jessner (eds), 8-20. Clevedon: Multilingual Matters.

Cenoz, J. 2003. The role of typology in the organization of the multilingual lexicon. In The multilingual lexicon, J. Cenoz, B. Hufeisen \& U. Jessner (eds), 103-116. Dordrecht: Kluwer.

Chomsky, N. 1965. Aspects of the Theory of Syntax. Cambridge MA: The MIT Press.

De Angelis, G. 2005. Interlanguage transfer of function words. Language Learning 55(3): $379-414$.

De Angelis, G. 2007. Third or Additional Language Acquisition. Clevedon: Multilingual Matters.

Ecke, P. \& Hall, C.J. 2000. Lexikalischer Fehler in Deutsch als Drittsprache: Translexikalischer Einfluss auf 3 Ebenen der mentalen Repräsentation. Deutsch alsFremdsprache 1: 31-37.

Fabbro, F. 2001. The bilingual brain: Bilingual aphasia. Brain and Language 79: 201-210.

Falk, Y. 2010. Gingerly Studied Transfer Phenomena in L3 Germanic Syntax. The Role of the Second Language in Third Language Acquisition. Utrecht: LOT Publications.

Falk, Y. \& Bardel, C. 2010. The study of the role of the background languages in third language acquisition. The state of the art. International Review of Applied Linguistics in Language Teaching. IRAL 48(2-3): 185-220.

Falk, Y. \& Bardel, C. 2011. Object pronouns in German L3 syntax: Evidence for the L2 status factor. Second Language Research 27(1): 59-82.

Flynn, S., Foley, C. \& Vinnitskaya, I. 2004. The cumulative-enhancement model for language acquisition: Comparing adults' and children's patterns of development in first, second and third language acquisition of relative clauses. International Journal of Multilingualism 1: 3-16. 
Hammarberg, B. 2001. Roles of L1 and L2 in L3 production and acquisition. In Crosslinguistic Influence in Third Language Acquisition: Psycholinguistic Perspectives, J. Cenoz, B. Hufeisen \& U. Jessner (eds), 21-41. Clevedon: Multilingual Matters.

Hufeisen, B. 1998. L3: Stand der Forschung: Was bleibt zu tun? In Tertiärsprachen. Theorien, Modelle, Methoden, B. Hufeisen \& B. Lindemann (eds), 169-184. Tübingen: Stauffenburg.

Hufeisen, B. 2010. Theoretische Fundierung multiplen Sprachenlernens - Faktorenmodell 2.0. Jahrbuch Deutsch als Fremdsprache 36: 191-198.

Hufeisen, B. \& Marx, N. 2007. How can DaFnE and EuroComGerm contribute to the concept of receptive multilingualism? Theoretical and practical considerations. In Receptive Multilingualism [Hamburg Studies on Multilingualism 6], J. ten Thije \& L. Zeevaert (eds), 307-322. Amsterdam: John Benjamins.

Jessner, U. 2006. Linguistic Awareness in Multilinguals. English as a Third Language. Edinburgh: EUP.

Kellerman, E. 1983. Now you see it, now you don't. In Language Transfer in Language Learning, S. Gass \& L. Selinker (eds), 112-134. Rowley MA: Newbury House.

Klein Gunnewiek, L. 2000. Sequenzen und Konsequenzen. Zur Entwicklung niederländischer Lerner im DeutschenalsFremdsprache. Amsterdam: Rodopi.

Krashen, S. 1981. Second Language Acquisition and Second Language Learning. Oxford: Pergamon Press.

Leung, Y.-k. L. 2005. L2 vs. L3 initial state: A comparative study of the acquisition of French DPs by Vietnamese monolinguals and Cantonese-English bilinguals. Bilingualism: Language and Cognition 8(1): 39-61. 
Lindqvist, C. 2010. Lexical cross-linguistic influences in advanced learners' French L3 oral production. International Review of Applied Linguistics in Language Teaching. IRAL 48(2-3): 131-157.

Meisel, J. 1983. Transfer as a second language strategy. Language and Communication 3: 1146.

Montrul, S., Dias, R. \& Santos, H. 2011. Clitics and object expressions in the L3 acquisition of Brazilian Portuguese: Structural similarity matters for transfer. Second Language Research 27: 21-58.

Paradis, M. 1994. Neurolinguistic aspects of implicit and explicit memory: Implications for bilingualism. In Implicit and Explicit Learning of Second Languages, N. Ellis (ed.), 393-419. London: Academic Press.

Paradis, M. 2004. A Neurolinguistic Theory of Bilingualism [Studies in Bilingualism 18]. Amsterdam: John Benjamins.

Paradis, M. 2008. Language and communication disorders in multilinguals. In Handbook of the Neuroscience of Language, B. Stemmer \& H.A. Whitaker (eds), 341-349. Amsterdam: Elsevier.

Paradis, M. 2009. Declarative and Procedural Determinants of Second Languages [Studies in Bilingualism 40]. Amsterdam: John Benjamins.

Ringbom, H. 1987. The Role of the First Language in Foreign Language Learning. Clevedon: Multilingual Matters.

Rothman, J. 2010. On the typological economy of syntactic transfer: word order and high/low attachment preference in relative clause interpretations in L3 Brazilian Portuguese. International Review of Applied Linguistics in Language Teaching. IRAL 48(2-3): $245-275$. 
Rothman, J. 2011. L3 Syntactic transfer selectivity and typological determinacy: The typological primacy model. Second Language Research 27(1): 107-127.

Rothman, J. \& Cabrelli Amaro, J. 2010. What variables condition syntactic transfer?: A look at the L3 initial state. Second Language Research 26(2): 189-218.

Rutherford, W. \& Sharwood Smith, M 1988. Consciousness-raising and Universal Grammar. Applied Linguistics 6(3): 274-281.

Sabourin, L. 2009. Neuroimaging and research into second language acquisition. Second Language Research 25(1): 5-11.

Sidtis, J.J. 2007. Some problems for representations of brain organization based on activation in functional imaging. Brain and Language 102(2): 130-140.

Singleton, D. \& O'Laoire, M. 2006. Psychotypology and the 'L2 factor' in cross-lexical interaction: an analysis of English and Irish influence in learner French. In Språk, lärande och utbildning $i$ sikte (Language, learning and education in sight), M. Bendtsen, M. Björklund, C. Fant \& L. Forsman (eds), 191-205. Vasa: Faculty of Education, ÅboAkademi.

Sjögren, Y. 2000. Multilingual conversations in Swedish. Ms.

Stedje, A. 1977. Tredjespråksinterferens i fritt tal - en jämförande studie (Third language interference in spontaneous speech - a comparative study). In Papers from the Conference on Contrasted Linguistics and Error Analysis, R. Palmberg \& H. Ringbom (eds), 141-158. Åbo: ÅboAkademi.

Towell, R. \& Hawkins, R. 1994. Approaches to Second Language Acquisition. Clevedon: Multilingual Matters.

Ullman, M.T. 2001. The neural basis of lexicon and grammar in first and second language: The declarative/procedural model. Bilingualism: Language and Cognition 4(2): 105122. 
Ullman, M.T. 2004. Contributions of memory circuits to language: The declarative/procedural model. Cognition 92: 231-270.

Ullman, M.T. 2005. A cognitive neuroscience perspective on second language acquisition: The declarative/procedural model. In Mind and Context in Adult Second Language Acquisition, C. Sanz (ed.), 141-178. Washington DC: Georgetown University Press.

Ullman, M.T. 2006. The declarative/procedural model and the shallow structure hypothesis. Applied Psycholinguistics 27(1): 97-105.

Vildomec, V. 1963. Multilingualism. Leyden: A.W. Sythoff.

Williams, S. \& Hammarberg, B. 2009. Language switches in L3 production: Implications for a polyglot speaking model. In Processes in Third Language Acquisition, B. Hammarberg (ed.) 28-73. Edinburgh: EUP. Originally 1998 in Applied Linguistics 19(3): 295-333.

Wood Bowden, H., Sanz, C. \& Stafford, C.A. 2005. Individual differences: Age, sex, working memory, and prior knowledge. In Mind and Context in Adult Second Language Acquisition. Methods, Theory, and Practice, C. Sanz, (ed.), 105-140. Washington DC: Georgetown University Press. 